\title{
Experimental Studies of Composite Sandwich Columns with Face/Core Debond under Axial Compression
}

\author{
Chen Yue, Zhu Xi , Zhu Zi-xu and Li hua-dong \\ Dept. of Naval Architecture Engineering, Naval Univ. of Engineering, Wuhan, China
}

\begin{abstract}
Experimental studies of buckling failure and debond propagation were carried out on composite sandwich columns with face/core debond. The edgewise compression tests were conducted on two type specimens. Namely, one containin throughthe-width rectangle face/core debond, and the other with embedded circular interfacial debond. High-speed photography technology has been used to record the debond propagating paths. Two main failure modes of collapse were recorded in the tests: core shear buckling and mixed buckling.
\end{abstract}

\section{Introduction}

Sandwich columns basically consist of two thin and stiff load carrying face sheets, which are adhered to the opposite sides of the core. The core serves as a spacer that keeps the face sheets apart, giving the sandwich columns a high bending stiffness to weight ratio. However, the debond located at face/core interface is one of the most common flaws in the composite sandwich structures. It might cause a significant reduction in stiffness and strength, and lead to the buckling of the structure.

Thus, investigation and analysis of mechanical behaviors for the composite sandwich structures with interfacial debond are of great interest to engineers, and many valuable papers have been published [1]-[3]. Theoretical prediction formulas of global buckling and local buckling for sandwich structures can be found in Allen's book [4]. Woo-Min [5] analyzed the debond buckling and growth of one-dimensional beam/plate by analytical methods. Singh S B [6] summarized the post-buckling behavior and progressive failure of rectangular laminates under in-plane shear loads. Hassan M [7] performed analytical and finite element calculations to investigate the effect of core density, and face/core debonds on the overall buckling behavior of the sandwich composites. Wang S[8]developed a more accurate analytical theory to express the post-buckling mode shape, then used the method to calculate the strain energy release rate and predicted the debond propagation behavior of one-dimensional debond include through-width debond in beams. Moslemian R [9] investigated sandwich columns with implanted through-width face/core debond both experimentally and numerically, and the numerical results were in overall agreement with experimental results. Jeyakrishnan R P [10] carried out experimental, theoretical and FEA analysis on the buckling characteristic of honeycomb sandwich panel.

The purpose of this work is to study the influence of the debond buckling and compressive properties of composite sandwich columns with embedded rectangle or circular face/core debonds. Experimental studies have been carried out to study the failure modes, debond growth path and ultimate load capability.

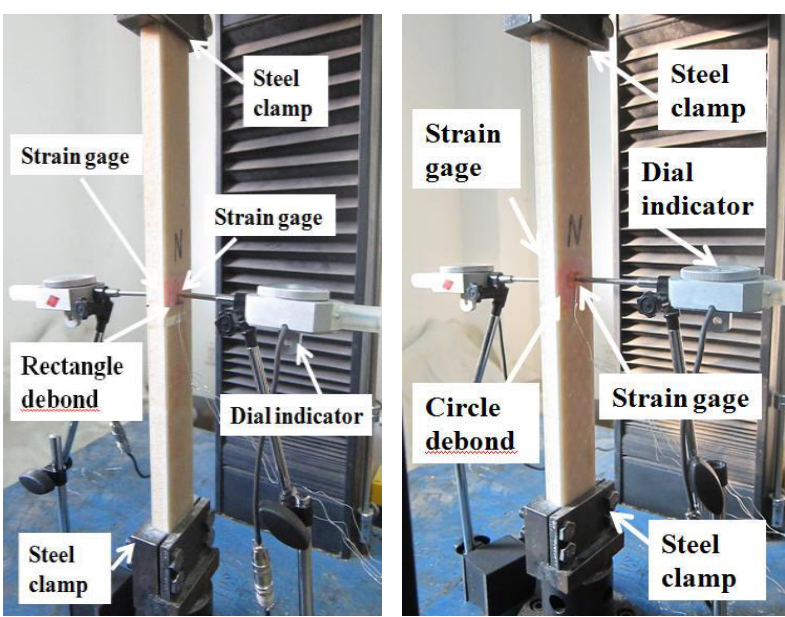

Figure 1. Loading diagram of specimens(a) rectangle debond (b) circular debond

\section{Experimental investigation}

\subsection{Test specimens}

Sandwich composite columns were manufactured by vacuum assisted resin infusion molding (VARIM) process. The sandwich composite columns consisted of core materials and pre-impregnated fiber material as face sheets. All layers of sandwich composite columns were laid along the direction of $0 \circ$. The fabric was plain weave 
SW220 glass fibers. The core was high-performance buoyancy foam Divinycell H100. Primarily two types of sandwich columns with rectangle $\mathrm{F} / \mathrm{C}$ debond and with circular $\mathrm{F} / \mathrm{C}$ debond were prepared and tested. The cores were bonded to the face sheets with epoxy adhesive. The debonds were defined by implanting non-stick red teflon cloth in the face/core interface before processing. Only one of the face/core interfaces contain the implanted debond. As seen in Fig. 1, the debonded side of the column was marked as $\mathrm{N}$, and the perfect side was marked as $\mathrm{S}$.

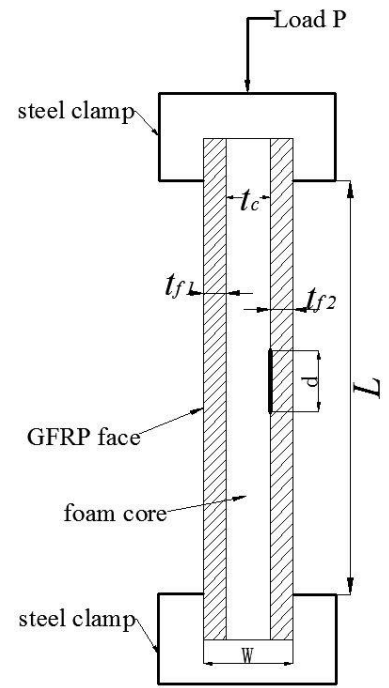

Figure 2. Geometric parameters of the specimen

Two types of specimens, namely containing rectangular face/core debond and circular interfacial debond, were fabricated to study the load capability and failure modes under edgewise compression. Three sets of both topologies sandwich composite columns with

different length $\mathrm{L}$, width $\mathrm{W}$, face sheet thickness $t_{\mathrm{f}}$,core thickness $t_{c}$ and debond sizes, as shown in Fig. 2, were studied in the damage propagation investigation.

\subsection{Test set-up}

In order to assess the influence of face/core debond, edgewise compression tests were performed on sandwich composite columns. Loading was applied by a electro-mechanical actuator with an axial capacity of $50 \mathrm{kN}$. Both ends of the specimens are clamped tightly to restrict the rotation. The compression tests were conducted with a displacement rate of $0.3 \mathrm{~mm} / \mathrm{min}$. A high-speed camera was used to track the debond propagation at a frame rate of 4000 images per second. To record the in-plane strains, strain gages were bonded in the centre of both sides. These polyimide backing strain gauges with the resistance $120.0 \pm 0.1 \Omega$ were produced by Shanxi Hanzhong Precise Electric Apparatus Co., LTD. The sensitive grid size of the strain gage is $5.0 \times 1.9 \mathrm{~mm}$, and the backing size is $8.7 \times 3.6 \mathrm{~mm}$.

\section{Compressive responses of sandwich composite columns}

\subsection{Failure modes}

The buckling modes of debond sandwich composite columns could be global, local or mixed types. In the compression test, core shear buckling, core failure, face crushing, face wrinkling and debond propagating were found. Table 1 shows the dimensions of all sandwich composite columns, as well as the observed failure modes. The debond size $50 \mathrm{~mm}$ covers the entire width of the specimens

Table 1. List of sandwich composite specimens with face/core debond

\begin{tabular}{cccccccc}
\hline $\begin{array}{c}\text { Specimens } \\
\text { type }\end{array}$ & $\begin{array}{c}\text { Specimens } \\
\text { number }\end{array}$ & $\begin{array}{c}\text { Length } \\
\mathbf{L} / \mathbf{m m}\end{array}$ & $\begin{array}{c}\text { Width } \\
\mathbf{W} / \mathbf{m m}\end{array}$ & $\begin{array}{c}\text { Skin } \\
\text { thickness } \\
\mathbf{t}_{\boldsymbol{f} 1}=\mathbf{t}_{\boldsymbol{f} 2} / \mathbf{m m}\end{array}$ & $\begin{array}{c}\text { Core } \\
\text { thickness } \\
\mathbf{t} \mathbf{c} / \mathbf{m m}\end{array}$ & $\begin{array}{c}\text { Debond } \\
\text { size } \\
\mathbf{/ m m}\end{array}$ & $\begin{array}{c}\text { Failure } \\
\text { modes }\end{array}$ \\
\hline \multirow{2}{*}{$\begin{array}{c}\text { Rectangle } \\
\text { debond }\end{array}$} & $\mathrm{R} 1$ & 400 & 50 & 2 & 16 & $10 \times 50$ & $\mathrm{CSB}+\mathrm{CF}+\mathrm{FC}$ \\
& $\mathrm{R} 2$ & 400 & 50 & 2 & 16 & $20 \times 50$ & $\mathrm{MB}+\mathrm{CF}+\mathrm{FC}$ \\
Circular & $\mathrm{R} 3$ & 400 & 50 & 2 & 16 & $40 \times 50$ & $\mathrm{MB}+\mathrm{CF}+\mathrm{FC}$ \\
debond & $\mathrm{C} 2$ & 400 & 50 & 2 & 16 & $\mathrm{R}=5$ & $\mathrm{CSB}+\mathrm{CF}+\mathrm{FC}$ \\
& $\mathrm{C} 3$ & 400 & 50 & 2 & 16 & $\mathrm{R}=10$ & $\mathrm{CSB}+\mathrm{CF}+\mathrm{FC}$ \\
\hline
\end{tabular}

Note: core shear buckling, core failure, mixed buckling and face crushing were abbreviated as CSB, CF, MB, FC, respectively.

As shown in Table 1, core shear buckling and mixed buckling were the dominant elastic macro-buckling modes for sandwich columns. Fig. 3(a) shows the failure mode of specimen $\mathrm{R} 1$ with a $10 \mathrm{~mm}$ rectangle face/core debond. Both Euler buckling and core shear buckling are global buckling modes, which often occurred in specimens containing relatively small debond. The main feature of the core shear buckling is that the core does not bent together with the face-sheets under compression, but the core shear occurred instead. The core shear buckling observed can be attributed to the weak shear stiffness of core.

The deformed mixed buckling configurations of the specimen C3 were showed in Fig. 3(b). Mixed buckling modes is a combination of global buckling and local buckling, which involved out-of-plane deflections for both face-sheets of the column. And we found that once the debonded face-sheet buckled, the debond tips propagated rapidly towards the ends of the specimen. Besides, crack kinking into the core was observed resulting in the crack propagating path changing from the interface to the core side. Typically and as a thumb rule, 
core shear failure happens at 45 degrees relative to the face sheets, whereas kinking happens under a 60 degree kinking angle, as seen in Fig. 3.

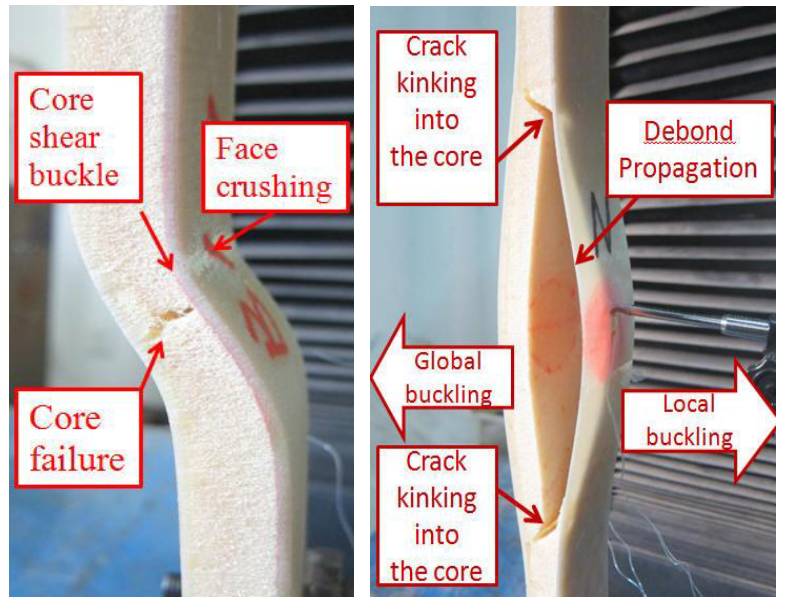

Figure 3. Failure modes: (a)specimen R1 (b) specimen C3

\subsection{Debond propagating}

The composite sandwich column R3 failed due to the crack propagation and face crushing. Representative photographs at various stages were taken by a high-speed camera during the testing. As shown in Fig. 4(a), under the compression load, firstly the structure became bended slightly, and the failure initiated in the form of debond on the interface. Subsequently, as the debonded zone of the face/core interface expanded, the debonded face-sheets were prone to buckle away from the core under compressive load. As we can see from Fig. 4(b), over the debonded zone, the face sheet buckled. Then, the debond may propagate along the interface or kink into the core.
We can see clearly from the Fig. 4(c) that the debond were propagated mainly on the face/core interface. Only a small amount of foam was peeled and adhered to the debonded face-sheet in Fig. 4(d). The debond may kinking into the core when the following inequality is satisfied:

$$
\left(\frac{\max G}{G_{\mathrm{I}, c r}}\right)_{\text {core }} \succ\left(\frac{G}{G_{\mathrm{cr}}(\gamma)}\right)_{\text {int }}
$$

The $G_{\mathrm{I}, c r}$ is the critical strain energy release rate for the core material in mode I, and $G_{\text {cr }}(\gamma)$ is the critical interfacial strain energy release rate. Slight crack kinked into the core resulting in the crack propagation path changed to the core side. With the crack propagation, out-plane bending tension strain and shearing strain may occur in the tips of the debond zone. And these interaction may cause shear failure of the foam. Eventually, the entire sandwich specimen collapsed in fiber compression failure and lost the capability of load bearing.

As shown in Fig. 4, for sandwich columns R3 with through-the-width face/core debond, both fronts of the debond propagated towards the specimen ends rapidly. While for specimens with embedded circular face/core debonds, the debond propagated perpendicularly along the compression direction until form a through-the-width debond. Then, the debond propagated along the compression direction. After propagation, both two types of specimens collapsed by face-sheet compression failure and core shear failure.
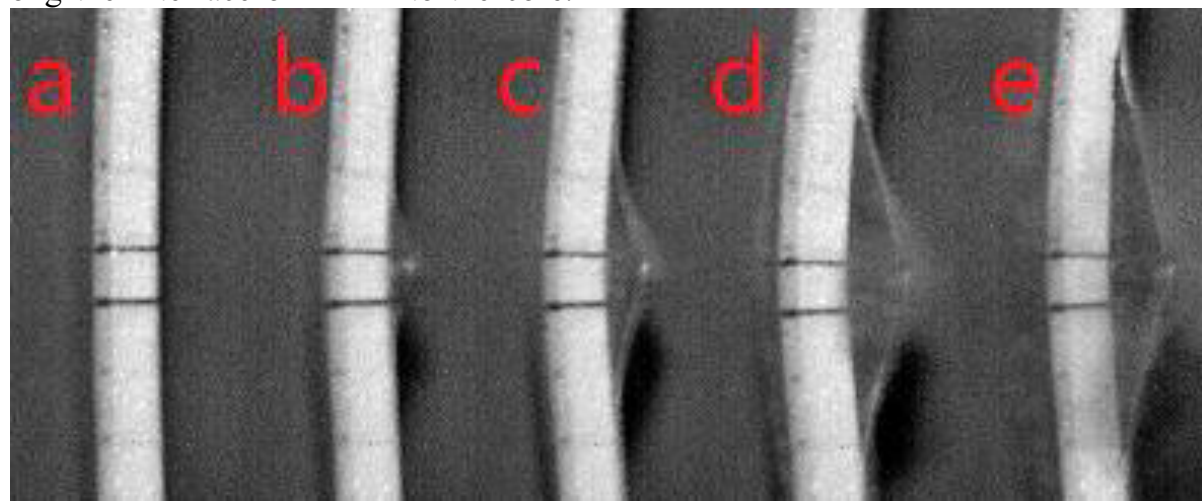

Figure 4. Photographs of the deformation history of sandwich column R3

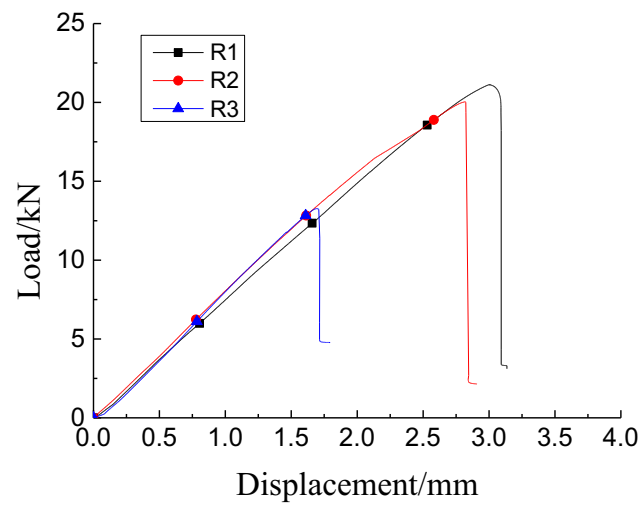

Figure 5. End shorting-Limit load curves of specimens R1-R3

\subsection{Load capability}

The load-shortening curves of all specimens are depicted in Fig. 5 and Fig. 6. The curves are almost linear after the initial stiffening region, and a reduction in the overall stiffness is observed at the final stage of the curve. As we all know, the overall stiffness was estimated as the tangent to the curves. It is evident that the increase of debond size weakened the ultimate load capability of the structure. The responses of the columns at this stage of loading were governed by a combination of buckling and debonding propagation. As the compressive load reached the critical load, core shear crushing and fiber compression failure 
were found. Simultaneously, the overall stiffness decreased, the resisting force of the column decreased sharply.

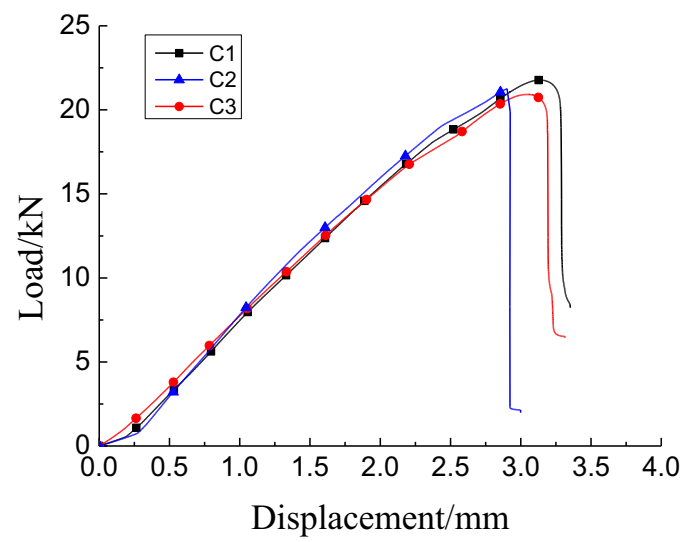

Figure 6. End shorting-Limit load curves of specimens C1-C3

\section{Concluding remarks}

The compressive response and failure mechanism of composite sandwich columns with rectangle or circular face/core debonds under edgewise compression were investigated in this paper. The main results can be outlined as the following:

During the experimental study, several modes of buckling and failure modes, namely, core shear buckling, mixed buckling, interfacial debonding, core shear failure and fiber compression failure, have been observed. Most specimens failed due to the delaminated buckling followed by rapid debond propagation. And the debond size has a significant effect on the buckling failure modes. Generally, as the increase of the debond size, the buckling load was on the decline. When the debond size exceeded a certain value, the failure mode changed from global buckling to mixed buckling.

\section{References}

1. Libove C, Butdorf S B. A general small-deflection theory for flat sandwich plates[M]. NASATN 1526, (1948).

2. Zenkert D. An introduction to sandwich construction[M]. EMAS, London, (1997).

3. Plantema F J. Sandwich construction: the bending and buckling of sandwich beams, plates and shells[M]. New York: John Wiley and Sons, 1966.

4. Allen H G. Analysis and Design of Structural Sandwich Panels[M]. Pergamon Press, London, (1969).

5. Woo M K., Chun G K. Debond buckling and growth of composite laminated plates with transverse shear deformation[J]. Composite Material, 29:2047 -2068, (1995).

6. Singh S B,Kumar A. Postbuckling response and failure of symmetric laminates under in-plane shear[J]. Composite Sciencen \& Technology, 58(12):1949-1960, (1988).

7. Hassan M, Syful I, Mrinal S, et al.Buckling of sandwich composites:effects of core-skin debonding and core density $[\mathrm{J}]$.Applied Composite Materials, 12(2):73-91, (2005).

8. Wang S, Harvey C M, Wang B, WatsonA. Post-local buckling-driven debond in bilayer composite beams[J]. Composite Structures, 133: 1058-1066, (2015).

9. Moslemian, R., Berggreen, C., Carlsson, L. A. and Avilés, F., "Failure Investigation of Debonded Sandwich Columns: An Experimental and Numerical Study", Journal of Mechanics of Materials and Structures, 4(7-8):1469-1487, (2009).

10. Jeyakrishnan P R, Chockalingam K K S K, Nara yanasamy R. Studies on buckling behavior of honeycomb sandwich panel[J]. International Journal of Advanced Manufacturing Technology, 65(5-8):803-815, (2013) 